\title{
Variation of Chemical and Morphological Properties of Different Parts of Prunus Amygdalus L. and Their Effects on Pulping
}

\author{
Ibtissem Moussa ${ }^{1}$, Ramzi Khiari ${ }^{1,2,3, *}$, Ali Moussa ${ }^{4,5}$, Ragab E. Abouzeid ${ }^{3,6}$, \\ Mohamed Farouk Mhenni ${ }^{1}$, Fouad Malek ${ }^{7}$ \\ ${ }^{1}$ Research Unity of Applied Chemistry \& Environment UR13 ES 63, University of Monastir, \\ 5000 Monastir, Tunisia. \\ ${ }^{2}$ Higher Institute of Technological Studies of Ksar Hellal, University of Monastir, Ksar \\ Hellal, Tunisia. \\ ${ }^{*}$ LGP2, Univ. Grenoble Alpes, CNRS, Grenoble INP, F-38000 Grenoble, France. \\ ${ }^{*}$ Textile Engineering Laboratory (LR11ES42), University of Monastir, 5070 Ksar-Hellal, \\ Tunisia. \\ ${ }^{*}$ National Engineering School of Monastir, University of Monastir, 5019 Monastir, Tunisia. \\ ${ }^{*}$ Cellulose \& Paper Department, National Research Center, Dokki, Cairo, PO 12622, \\ Egypt. \\ ${ }^{* 7}$ Laboratory of Organic, Macromolecular Chemistry and Natural Products, Faculty of \\ Sciences, Mohammed First University, Oujda 60000, Morocco.
}

\begin{abstract}
CHEMICAL and morphological of Prunus amygdalus L. characterization (shells and stems) were studied in order to assess their potentiality for chemical pulp. In this work, a simple, rapid and sensitive analytical method for the determination of monosaccharide composition in almond shells and stems polysaccharide was developed and validated. The soda-anthraquinone process was also applied in order to evaluate pulp properties. The effects of delignification and bleaching process were statistically investigated by employing response surface methodology. The isolated fibers were investigated and characterized using several techniques such as gel permeation chromatography, X-ray diffraction, morfi analyzer and scanning electron microscope. The obtained results can be considered as a potential source of cellulose for the production of cellulose derivatives, cellulose pulp for papermaking applications and natural fibres reinforced polymer composite.
\end{abstract}

Keywords: Cellulose fiber, Prunus amygdalus L., Characterization, Box-Behnken Design.

\section{Introduction}

Non-wood resources are important raw materials in many countries where wood is not available and/ or in sufficient quantities to meet the large demand for pulping and papermaking application. In general, non-woods differ somewhat from wood in their chemical composition and properties, which in turn have a direct influence on the selection of delignification and bleaching processes. In recent years, the use of non-wood resources to produce pulp and paper is growing interest. Almond shells and stems are a cheap and annually renewable resource suitable for producing natural cellulose fibers. This plant could be one of the important annual agricultural residues, which produced in many countries such as the USA, Syria, Italy, Morocco, Turkey, and Tunisia[1-3]. Nowadays, almond cultivation is increasing due to its huge demand for food among the mass people. Almond shells are a lignocellulosic agriculture by-product that does not have an industrial application yet, and it is usually incinerated or dumped. It has some interesting features like high volume and low value. According to FAO (FAOSTAT data), Tunisia is ranked as the producing country of almond with about $3.8 \%$ of the total world production $[4,5]$. Thus, Tunisia annual production of almond shells is 36000 tons by considering that the shells have about $60 \%$ of the almond fruit weight. This paper deals with the morphological and chemical properties of the two parts of the almond tree as well as their soda-anthraquinone pulping optimization. Soda-anthraquinone cooking is considered the most suitable process for pulping of non-wood raw materials with good results [6-9], if considering the advantages, they provide, such as: (i) high throughput resulting from the use of relatively short pulping times; (ii) good yields; (iii) applicability to both wood

*Corresponding authors e-mails: r_abouzeid2002@yahoo.com; khiari_ramzi2000@yahoo.fr DOI: 10.21608/EJCHEM.2018.4827.1429

C2017 National Information and Documentation Center (NIDOC) 
and non-wood raw materials; (iv) reusability of cooking liquors. The monosaccharide composition analysis of polysaccharides is the most important parameter for the discovery of its physicochemical properties and structure[10-16]. The aim of the present study was to develop a simple and rapid ion chromatography method for the quantification of the monosaccharide composition without sample derivatization. In conclusion the main objectives of this work is to : (a) determination of the chemical compositions of the raw material (b) the study the effect of the delignification conditions into the pulping yield and Kappa number, in order to determine the best pulping conditions, (c) optimization of the bleaching steps of cellulose pulp. The obtained fibers were characterized investigated using gel permeation chromatography (GPC), X-ray diffraction (XRD), morfi analyzer and scanning electron microscope (SEM). The obtained results were discussed and compared with those available in the literature related to wood-, non-wood- and annual plant crops-based papers $[4,6,8,9,13,15]$.

\section{Materials and Methods}

\section{Materials}

Raw material collection

Two parts from the almond plant namely shells and stems were investigated. They were collected from Monastir in August 2017. Then, they were rinsed and dried under natural condition during the month of September 2017. After that, they were chopped to $2-3 \mathrm{~cm}$ for morphological characterizations. For chemical composition determination, the almond samples were ground and 40-60 mesh fractions were selected. The procedures were performed according to standard T264 cm-07.

\section{Chemical analysis}

The chemical compositions of the two parts were determined according to the following TAPPI standard methods: the solubility in hot and cold water (T207 cm-08), in $1 \% \mathrm{NaOH}$ (T212 om07), and in ethanol-toluene (T204 cm-07). The ash content was quantified using the standard method T211 om-07. The Klason lignin, holocellulose, and $\alpha$-cellulose were determined according to the following TAPPI standard methods T222 om-06, Wise et al. (1946)[17]. and T203 cm-99, respectively. All the measurements were carried out at least in triplicate and the experimental error was within $5 \%$.

\section{Monosaccharide composition}

\section{Colorimetric method}

This method based on colorimetric technique. Simple sugars, oligosaccharides, polysaccharides, and their derivatives, containing the methyl ethers with free or potentially free reducing groups, deliver an orange-yellow color when treated with phenol and concentrated sulfuric acid. The color is fixed. Working with this phenol-sulfuric acid reaction, a method has been developed to determine submicro amounts of sugars and related entities.

\section{Chromatographic method: Ion Chromatography}

This method employs a two-step acid hydrolysis. Primary hydrolysis of $350 \mathrm{mg}$ sample was performed with $3 \mathrm{~mL} 72 \%$ (w/w) $\mathrm{H}_{2} \mathrm{SO}_{4}$ for 1 hour at $30^{\circ} \mathrm{C}$. Hydrolysates were diluted to $4 \%$ (w/w) $\mathrm{H}_{2} \mathrm{SO}_{4}$ with distilled water. A secondary hydrolysis performed for 1 hour at $120^{\circ} \mathrm{C}$ in the autoclave $(1 \mathrm{bar})$ to fractionate the biomass into forms that are more easily quantified. Fucose was added as an internal standard. The hydrolysates were diluted to $200 \mathrm{~mL}$ with $\mathrm{H}_{2} \mathrm{O}$, and filtered through $0.45 \mu \mathrm{m}$ Teflon syringe filter. Then, $10 \mu \mathrm{L}$ of hydrolysates were injected into the chromatographic system.

\section{Morphologyfibres}

The obtained fibres were characterized using SEM device a LEO scanning electron microscope (LEO-400) instrument. In addition, the morphological properties of the prepared fibres were also studied using a MORFI analyser. The main parameters of the fibre (length, width, $\%$ of fine elements) were evaluated by image analysis of a diluted suspension flowing in a transparent flat channel observed by a CCD video-camera. The test was repeated at least in triplicate.

Infrared spectroscopy (FT-IR), X-ray Diffraction and thermogravimetric analysis

The FT-IR analysis of obtained fibres was carried out with a Perkin-Elmer 1000 spectrometer equipped with a diamond ATR accessory. The spectra were obtained in the wave number range of $600-4000 \mathrm{~cm}^{-1}$ with 32 scans. The XRD of the materials was established using X-ray diffraction. The samples were examined using an X-ray diffractometer (D8-Advance Bruker AXS GmbH) at room temperature with a monochromatic $\mathrm{CuK} \alpha$ radiation source $(\lambda=0.154 \mathrm{~nm})$ in a step-scan mode with a $2 \theta$ angle ranging from $5^{\circ}$ to $60^{\circ}$ with a step of 0.04 and a scanning time of $5.0 \mathrm{~min}$. The crystallinity degree was determined using the 
method described by Segal et al.[18]. The thermal gravimetric analysis was characterized using a TA instrument Q-50 thermogravimetric analyzer (TA instruments, USA). The samples were heated in the range from $30^{\circ} \mathrm{C}$ to $800^{\circ} \mathrm{C}$ at a heating rate of $10^{\circ} \mathrm{C} \cdot \mathrm{min}^{-1}$, under a stream of air. All the measurements were carried out at least in duplicate and the experimental error was within $5 \%$.

\section{Methods}

\section{Pulping}

Pulps were produced by a conventional delignification process with soda-anthraquinone, which has already been defined for non-woody annual plants [4-9]. To optimize the pulping conditions, several parameters can affect obtained results (pulp yield and Kappa number). These parameters are temperature, time and soda concentration. To evaluate their effects, experiments were carried out using Box-Behnken Design (BBD). Each parameter was varied across three levels $(-1,0$, and +1$)$ as listed in Table 1 . The range of analyzed factors was chosen based on literature studies and the authors' experience. After pulping, the obtained samples were washed several times with distilled water until the liquid reached a neutral $\mathrm{pH}$.

\section{Bleaching process}

The bleaching process was completed by adding a solution of soda $(\mathrm{pH}=9-13)$, sodium hypochlorite $(30-70 \%)$ at temperature varied from 30 to $60^{\circ} \mathrm{C}$ for $60-180 \mathrm{~min}$. The mixture was allowed to filtered and purified by antichlorine treatment. To investigate the optimal conditions of the bleaching treatment of fiber extracted from almond shells and stems, a BoxBehnken experimental design was used. Variable factors are $\mathrm{pH}$, temperature, sodium hypochlorite concentration and time, with three levels of each parameter as shown in Table 2. The pulps quality was studied by determining two response variables: Bleaching yield and Kappa number.

\section{Experimental design}

$Y=\beta_{0}+\sum_{i=1}^{n} \beta_{i} X_{i}+\sum_{i, j=1}^{n} \beta_{i j} X_{i} X_{j}+\sum_{i=1}^{n} \beta_{i i} X^{2}(1)$

Where: $\mathrm{Y}$ is a response (peak area); $\beta 0$, $\beta$ iand $\beta \mathrm{ijare}$ the model coefficients; $\mathrm{Xi}$ and $\mathrm{Xj}$ are the coded independent variables.

TABLE 1. Box-Behnken design used in the soda-anthraquinone process.

\begin{tabular}{|c|c|c|c|c|c|c|c|}
\hline \multirow{2}{*}{ Factors } & & & & \multirow{2}{*}{ Symbols } & \multicolumn{3}{|c|}{ Levels } \\
\hline & & & & & -1 & $\mathbf{0}$ & 1 \\
\hline \multicolumn{4}{|c|}{$\begin{array}{l}\text { Temperature }\left({ }^{\circ} \mathrm{C}\right) \\
\text { Time (min) }\end{array}$} & $\begin{array}{l}\mathbf{X}_{1} \\
\mathbf{X}_{2}\end{array}$ & $\begin{array}{l}80 \\
60\end{array}$ & $\begin{array}{l}110 \\
120\end{array}$ & $\begin{array}{l}140 \\
180\end{array}$ \\
\hline \multicolumn{4}{|c|}{ Sodium hydroxide concentration (\%) } & $x_{3}^{2}$ & 8 & 12 & 16 \\
\hline \multirow{3}{*}{ Expt. $\mathbf{N}^{\circ}$} & \multicolumn{3}{|c|}{ Factors } & \multicolumn{4}{|c|}{ Responses } \\
\hline & \multirow{2}{*}{$\mathbf{X}_{1}$} & \multirow{2}{*}{$\mathbf{X}_{2}$} & \multirow{2}{*}{$\mathbf{X}_{3}$} & \multicolumn{2}{|c|}{ Almond shells } & \multicolumn{2}{|c|}{ Almond stems } \\
\hline & & & & Yield (\%) & Kappa Number & Yield (\%) & Kappa Number \\
\hline 1 & -1 & -1 & 0 & 53.48 & 61.38 & 54.42 & 54.03 \\
\hline 2 & 0 & -1 & 1 & 64.79 & 56.20 & 51.01 & 48.27 \\
\hline 3 & 1 & 0 & 1 & 48.34 & 52.08 & 47.37 & 47.38 \\
\hline 4 & 0 & 0 & 0 & 29.41 & 40.12 & 44.42 & 41.42 \\
\hline 5 & 0 & -1 & -1 & 30.44 & 43.33 & 40.30 & 38.09 \\
\hline 6 & 0 & 1 & -1 & 39.39 & 45.92 & 45.26 & 47.02 \\
\hline 7 & 1 & -1 & 0 & 54.93 & 53.27 & 45.94 & 47.42 \\
\hline 8 & -1 & 0 & 1 & 56.78 & 55.17 & 51.47 & 47.51 \\
\hline 9 & 1 & 1 & 0 & 28.52 & 46.08 & 44.53 & 39.05 \\
\hline 10 & -1 & 1 & 0 & 47.81 & 52.29 & 47.09 & 47.16 \\
\hline 11 & -1 & 0 & -1 & 50.35 & 57.76 & 48.17 & 47.01 \\
\hline 12 & 1 & 0 & -1 & 46.47 & 52.05 & 46.34 & 41.08 \\
\hline 13 & 0 & 0 & 0 & 54.97 & 60.11 & 52.19 & 55.93 \\
\hline 14 & 0 & 0 & 0 & 48.41 & 52.49 & 46.83 & 46.72 \\
\hline 15 & 0 & 1 & 1 & 64.06 & 54.86 & 52.10 & 48.66 \\
\hline
\end{tabular}


TABLE 2. Box-Behnken design used in the bleaching process.

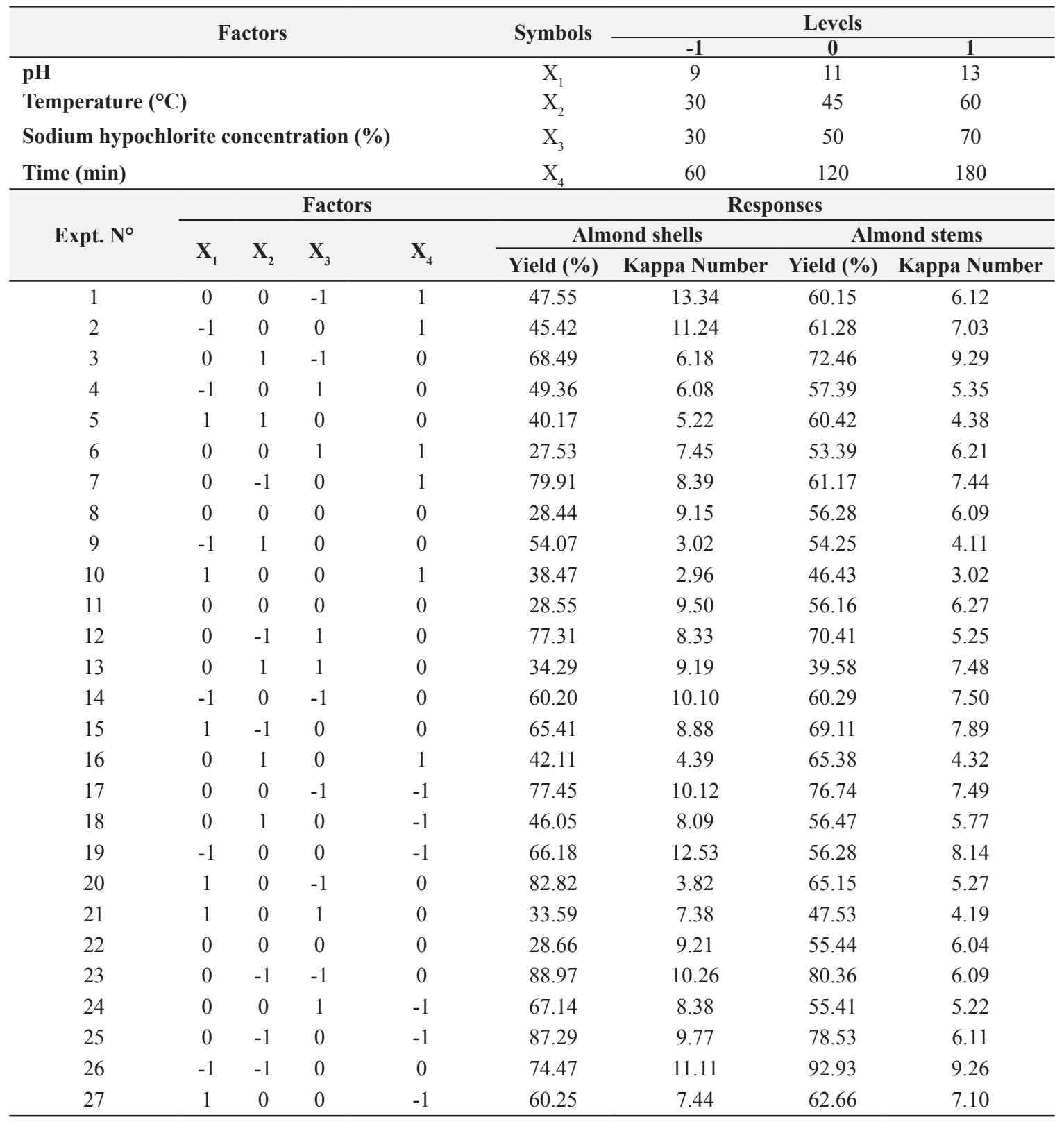

The total of experimental runs was analyzed by BBD to fit the second-order polynomial model (Eq. 1). Minitab (Version 17) software package was used to perform the analysis of variance (ANOVA). The P values of less than 0.05 were considered to be statistically significant.

Where: $\mathrm{Y}$ is a response (peak area); $\beta_{0}, \beta_{\mathrm{i}}$ and $\beta_{\mathrm{ij}}$ are the model coefficients; $X_{i}$ and $X_{j}$ are the coded independent variables.

\section{Results and Discussion}

Characterization of the raw material

Egypt. J. Chem. 62, No. 2 (2019)
The chemical composition and structure of components from different morphological parts of the almond plant was established and displayed in Table 3 [19-27]. The standard deviations of the three replicates in each test with respect to the means were always less than $5 \%$. The highest amount of cellulose $(37.51 \%)$ and hemicellulose (26.71\%) were found in shells, but lignin $(34.35 \%)$ was higher in stems. $\alpha$ - cellulose content of the raw material is the prime factor in selecting a material for pulping. $\alpha$ - cellulose in almond shells was considerably higher than the other part. 
TABLE 3. Chemical and physical characterization of almond shells and stems.

\begin{tabular}{|c|c|c|c|}
\hline Components & & Almond shells & Almond stems \\
\hline Cold water extractives (\%) & & $5.68 \pm 0.27$ & $12.17 \pm 0.10$ \\
\hline Hot water extractives (\%) & & $11.69 \pm 1.52$ & $16.70 \pm 1.19$ \\
\hline Ethanol-toluene extractives (\%) & & $9.82 \pm 2.09$ & $7.02 \pm 1.69$ \\
\hline $1 \% \mathrm{NaOH}$ extractives $(\%)$ & & $21.34 \pm 4.48$ & $29.01 \pm 4.12$ \\
\hline Ash (\%) & & $2.35 \pm 0.38$ & $3.39 \pm 0.47$ \\
\hline Klason Lignin (\%) & & $24.01 \pm 2.64$ & $34.35 \pm 3.22$ \\
\hline Soluble lignin (\%) & & $1.57 \pm 0.32$ & $0.76 \pm 0.11$ \\
\hline Holocellulose (\%) & & $64.22 \pm 2.66$ & $50.66 \pm 2.57$ \\
\hline \multirow{2}{*}{ Hemicellulose (\%) } & TAPPI method & $26.71 \pm 2.68$ & $19.25 \pm 1.44$ \\
\hline & Ion chromatography (\%) & 26.86 & 18.61 \\
\hline \multirow{2}{*}{$\alpha$-cellulose (\%) } & TAPPI method & $37.51 \pm 3.44$ & $31.41 \pm 3.79$ \\
\hline & Ion chromatography (\%) & 38.16 & 33.60 \\
\hline \multirow{2}{*}{ Total sugar (\%) } & Dosage Dubois (\%) & $60.47 \pm 3.07$ & $46.58 \pm 2.45$ \\
\hline & Ion chromatography $(\%)$ & $65.03 \pm 3.51$ & 52.22 \\
\hline Total charge $\left(\mu\right.$ eq. $\left.\mathrm{g}^{-1}\right)$ & & $65 \pm 1.53$ & $80.00 \pm 1.25$ \\
\hline $\mathrm{pH}_{\mathrm{pzc}}$ & & 4.65 & 6.4 \\
\hline
\end{tabular}

TABLE 4. Chemical composition of different plant materials.

\begin{tabular}{|c|c|c|c|c|c|}
\hline & Plant materials & References & Cellulose & Hemicellulose & Lignin \\
\hline \multirow{5}{*}{ Hardwoods } & White birch & [19] & 41 & 36.2 & 18.9 \\
\hline & Redmaple & {$[20]$} & 44.1 & 29.2 & 24 \\
\hline & Hybrid poplar & {$[20]$} & 41.7 & 20.2 & 29.3 \\
\hline & Encalyptus viminalis & [20] & 41.7 & 14.2 & 31 \\
\hline & Populus de ltoides & [19] & 46 & 19 & 24 \\
\hline \multirow{25}{*}{ Softwoods } & Pinus banksiana & [20] & 41.6 & 25.6 & 28.6 \\
\hline & Pinus pinaster & {$[20]$} & 42.9 & 17.6 & 30.2 \\
\hline & Pinus radiata & {$[20]$} & $42-50$ & $24-27$ & 20 \\
\hline & Fir & {$[20]$} & 43.9 & 26.5 & 28.4 \\
\hline & White Fir & [19] & 44 & 11 & 27 \\
\hline & RedFir & [19] & 43 & 12 & 27 \\
\hline & Corn cobs & [19] & $33.7-41.2$ & $31.9-36$ & $6.1-15.9$ \\
\hline & Sugarcane Bagasse & [19] & $35-41.3$ & $27-37.5$ & $10-20$ \\
\hline & Wheat Straw & {$[19]$} & $32.9-50$ & $24-35.5$ & $8.9-17.3$ \\
\hline & Rice Straw & [21] & $36.2-47$ & $19-24.5$ & $9.9-24$ \\
\hline & Corn stalk & [22] & $35-39.6$ & $16.8-35$ & $7-18.4$ \\
\hline & Rye straw & {$[19]$} & 37.6 & 30.5 & 19 \\
\hline & Flax & {$[19]$} & 34.9 & 23.6 & 22.3 \\
\hline & Roundup soybean & [19] & 34.5 & 24.8 & 19.8 \\
\hline & Vine shoots & [22] & $35.6-38.3$ & $20.6-35$ & $22.8-23.4$ \\
\hline & Vine stems & [23] & 35 & 30.4 & 28.1 \\
\hline & Vine shoots & [22] & 41.1 & 26 & 20.3 \\
\hline & Posidonia oceanica & [24] & 40 & 21.8 & 29.8 \\
\hline & Date palm rachis & [24] & 45 & 29.8 & 27.2 \\
\hline & Sorghum stalks & [22] & 42 & 29.7 & 13.4 \\
\hline & Amaranth & {$[22]$} & 32 & 26.4 & 13.2 \\
\hline & Jerusalem artichoke & [22] & 29 & 22.6 & 14.7 \\
\hline & Cynara Cardunculus L. & {$[25]$} & 40.5 & 32.3 & 25.4 \\
\hline & Bagasse & {$[26]$} & 40 & 30 & 20 \\
\hline & Corn stalks & [27] & 35 & 25 & 35 \\
\hline \multirow{9}{*}{$\begin{array}{c}\text { Annual and } \\
\text { perennial } \\
\text { plants }\end{array}$} & Flax & [27] & 71 & 21 & 2 \\
\hline & Hemp & [27] & 70 & 22 & 6 \\
\hline & Istle & {$[27]$} & 73 & $4-8$ & 17 \\
\hline & Jute & {$[27]$} & 71 & 14 & 13 \\
\hline & Kenaf & [28] & 36 & 21 & 18 \\
\hline & Wheat straw & [29] & 30 & 50 & 15 \\
\hline & Ramie & {$[22]$} & 76 & 17 & 1 \\
\hline & Sisal & {$[22]$} & 73 & 14 & 11 \\
\hline & Sunn & {$[22]$} & 80 & 10 & 6 \\
\hline
\end{tabular}


Table 4 shows published data for some agricultural residues, non-wood, hardwood, and softwood. It can be seen, that the lignin content of Prunus amygdalus exceeded those of other agricultural residues [2-10, 19-27]. The highest content of $\alpha$-cellulose and hemicellulose are of date palm rachis, which are similar to those of hardwood and softwood. The content of $\alpha$-cellulose and hemicellulose of almond shells and stems are similar to those of agricultural residues and alternative plants [2-10, 19-27]. On the other hand, the lignin content is higher than of some agricultural residues. The chemical composition of the ground Tunisian almond shells studied in this work is summarized in Table 5 , which also includes the corresponding data from previous studies by way of comparison. The differences between the reported values for the studied raw materials may have arisen from the use of different procedures, and the origin and variety of the raw material used. There is no significant difference between Tunisian, Iran and Portugal almond shells in terms of chemical composition [2-10, 19-27]. The monosaccharide composition of almond shells and stems are also determined. In fact, there was a significant difference in the monosaccharide composition of shells and stems. Glucose and xylose are the main components of almond shells and stems, while galactose and arabinose were present in relatively minor quantities. In conclusion, due to the acceptable amount of holocellulose, almond shells and stems can be considered as a potential source of cellulose for the production of cellulose derivatives, cellulose pulp for papermaking applications and natural fibres reinforced polymer composite.

\section{Analysis of the pulping treatment}

There are 15 sets of the experiment from the compilation of RSM for the study in order to determine the optimum reaction of delignification as shown in Table 1. By comparing the data in Table 1, it shows that a yield of cellulose and Kappa number varies with changes of process parameters. Hence, further analysis was conducted to study the influence of extraction process parameters on yield and Kappa number. Figure 1 shows the main effects plot for pulp yield and Kappa number, respectively. For the two studied materials, the temperature is the factor, which has the most significant effect on the responses. The effect of temperature on the pulp yield and residual lignin were examined by varying the temperature from 80 to $140^{\circ} \mathrm{C}$ with a constant $\mathrm{pH}$ and pulping time.
There was a significant decrease in the pulp yield and residual lignin with increasing temperature. This decrease was due to the solubilization of the soluble substances in hot water and the oxidation and solubilization of lignin. Less effect is given by soda concentration. However, a few variations are caused by the pulping time.

The statistical software Minitab 17 was used to design experiments, to determine the coefficients of linear, quadratic and interaction terms, and to build the quadratic model and response surface plots. The second-order polynomial equation for the yield of almond shells (), the Kappa number of almond shells (, the yield of almond stems (), and the Kappa number of almond stems ( are shown in Eqs.(2) -(5) below.

$$
\begin{aligned}
& \text { Yied }_{\text {ish }}\left(Y_{6}\right)=48.19-11.81 X_{1}-2.37 X_{2}-4.32 X_{3}-4.76 X_{1}^{2}+1.07 X_{2}^{2}+3.11 X_{3}^{2}-(2) \\
& \text { 1.79 } X_{1} X_{2}-5.09 X_{1} X_{3}-0.27 X_{2} X_{3}, R^{2}=83.80 \% \\
& \text { Kappa Number }=52.28-6.23 X_{1}-1.724 X_{2}-4.114 X_{3}-1.150 X_{1}^{2}-0.022 X_{2}^{2}+ \\
& 1.043 X_{3}^{2}+0.625 X_{1} X_{2}-1.430 X_{1} X_{3}-2.227 X_{2} X_{3} ; R^{2}=99.55 \%
\end{aligned}
$$

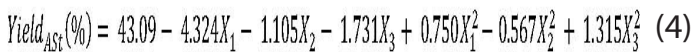

$$
\begin{aligned}
& -1.035 X_{1} X_{2}+0.257 X_{1} X_{3}+0.790 X_{2} X_{3}, R^{2}=97,09 \% \\
& \text { Kappa Number }{ }_{A S t}=47.09-5.811 X_{1}-1.236 X_{2}-0.877 X_{3}-1.537 X_{1}^{2}-0.117 X_{2}^{2}+(5) \\
& 0.460 X_{3}^{2}+1.578 X_{1} X_{2}+1.715 X_{1} X_{3}+0.215 X_{2} X_{3} ; R^{2}=94.67 \%
\end{aligned}
$$

Where: $\mathrm{X}_{1}$ : temperature $\left({ }^{\circ} \mathrm{C}\right), \mathrm{X}_{2}$ : time $(\mathrm{min})$, and $\mathrm{X}_{3}$ : sodium hydroxide concentration $(\%)$.

The value of the determination coefficient $\left(\mathrm{R}^{2}>80 \%\right)$ indicates a good relationship between the predicted and experimental values. All the results indicate that the model developed is successful. With these obtained models, it is possible to predict with considerable adequacy the responses under any given experimental conditions within the limits of the variables studied.

Figure 2 presents the obtained contour plots of predicted values of pulp yield. Results showed that the lowest values of pulp yield, similar to the chemical pulp, was obtained with large values of temperature, time and concentration of soda. These lowest yields can be increased by pulping at a lower temperature and a low value of the concentration of soda or time. The use of a low concentration of caustic soda would result in lowering the consumption of chemical products and an increase in the pulp yield. The optimum conditions obtained by Box-Behnken statistical

Egypt. J. Chem. 62, No. 2 (2019) 

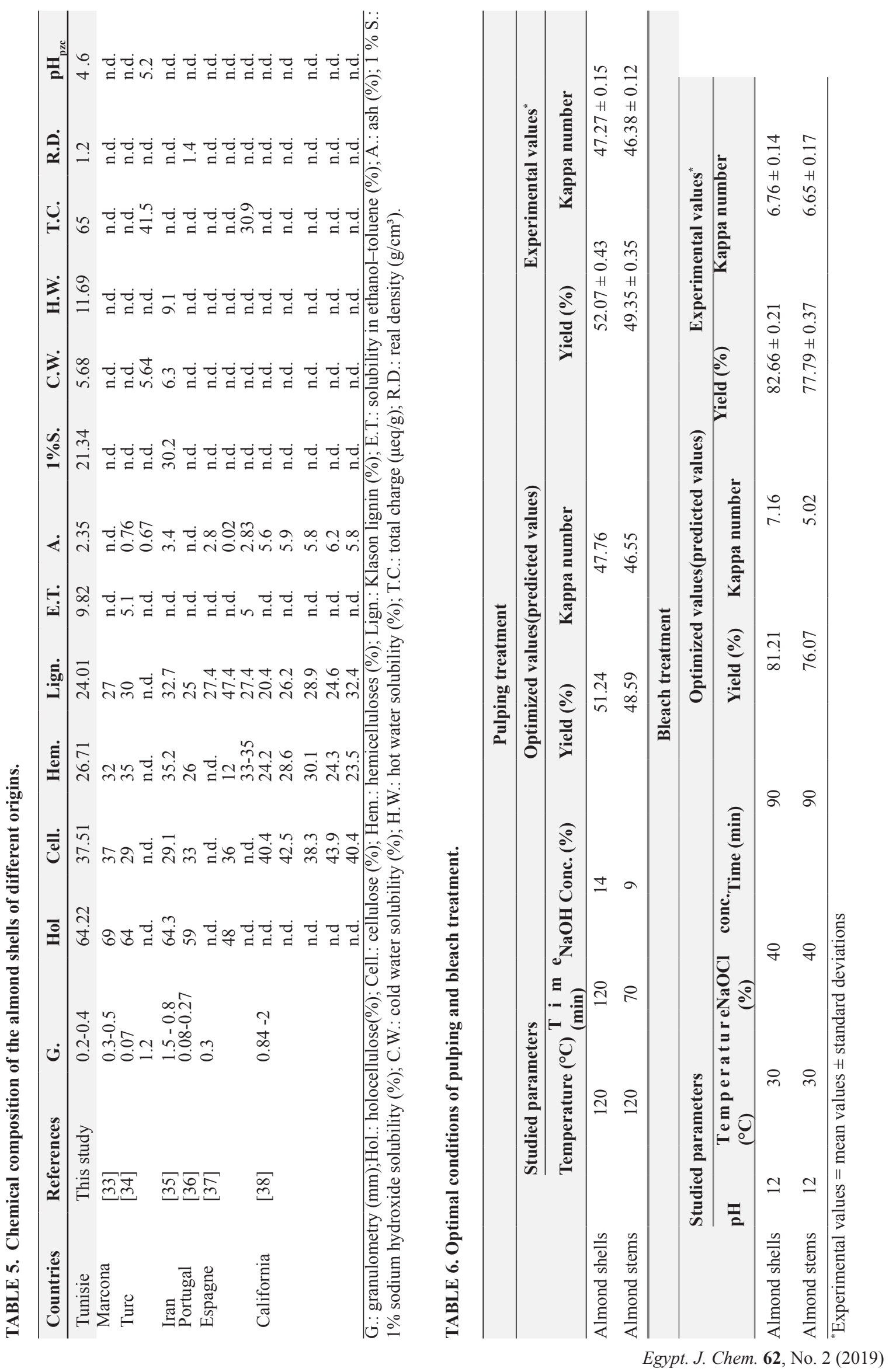
Pulping

(a)

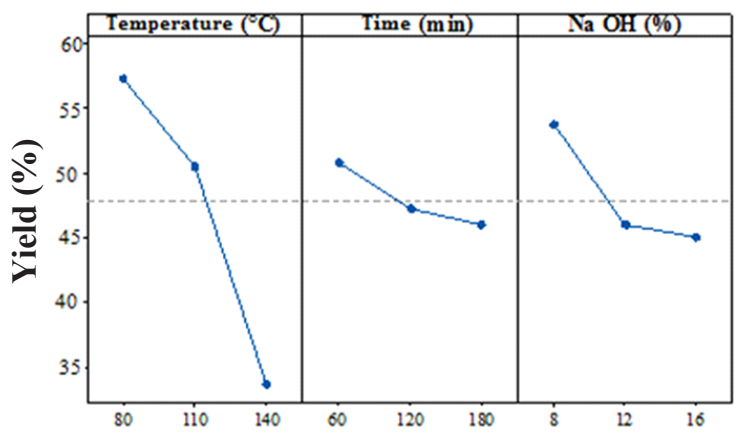

(b)

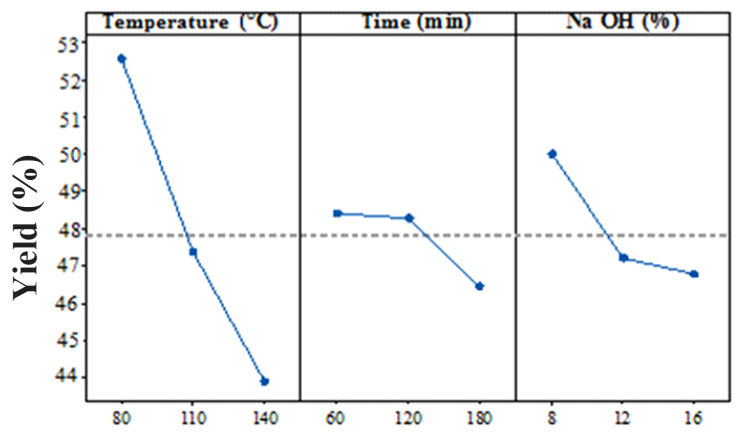

Bleaching

(a)

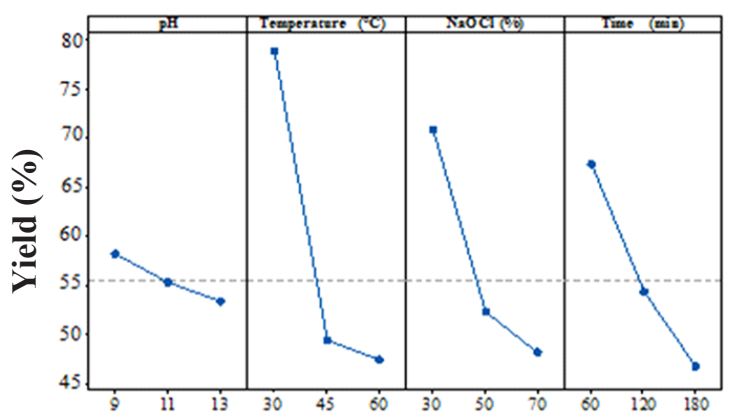

(b)

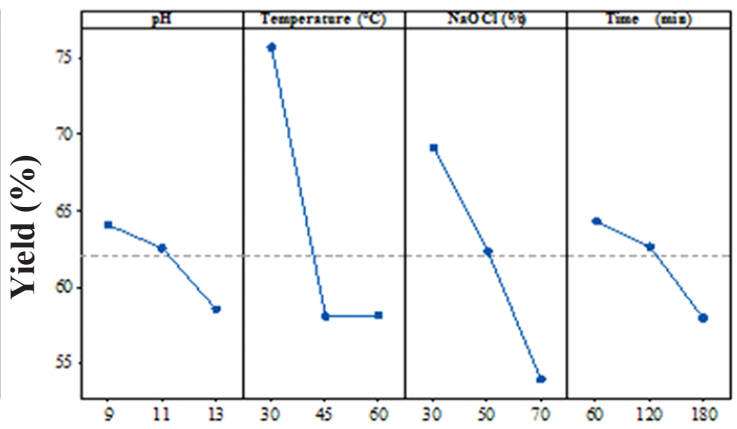

Fig. 1. Main effects plot for yield of (a) almond shells and (b) stems.

design are determined to maximize the production of pulp. The result of the second-order polynomial model developed indicated that the optimal conditions for the delignification conditions are listed in Table 6. To check the validity of the optimized conditions, experiments were realized to evaluate the experimental results versus predicted values using the model equation. The experiments were repeated three times and the average values were shown in Table 6 . The values obtained through confirmation experiments are within $95 \%$ of predicted values. This shows that the developed quadratic models are well-suited. It is also evident that the optimal values are valid within the specified range of process variables.

\section{Analysis of the bleach treatment}

Table 2 shows the 27 experiments composed by Minitab 17 software, based on a fourindependent variable, three-level $(-1,0$ and +1$)$ Box-Behnken. The real values and coded values of independent variables are also shown in Table 2. Figure 2 shows the variation of the pulp yield with the changes in temperature, $\mathrm{pH}$, time, and hypochlorite concentration. It shows that the highest and lowest variations in the highest pulp yield were caused by changes in temperature and $\mathrm{pH}$, respectively. The $\mathrm{pH}$ is a very important variable for installations containing chlorine and water as it decides how dominant form is chlorine. The proportion of chlorine, hypochlorous acid and hypochlorite in solution depends on $\mathrm{pH}$. The acid hypochlorousis considered destructive to the cellulose and therefore the bleaching is avoided in the $\mathrm{pH}$ range of 2 to 9 . It is essential to maintain the $\mathrm{pH}$ at a suitable level for a hypochlorite bleaching to prevent the attack of the cellulose. Hydrochloric acid must be neutralized to prevent the $\mathrm{pH}$ from falling in the area or hypochlorous acid is active. For each starting material, the $\mathrm{pH}$ improves the quality of pulp without losing yield.

During this part, the objective is to model the responses as a function of the process parameters $(\mathrm{pH}$, temperature, time and sodium hypochlorite concentration) and their interactions. The coefficients of quadratic models fitted for the yield of

Egypt. J. Chem. 62, No. 2 (2019) 


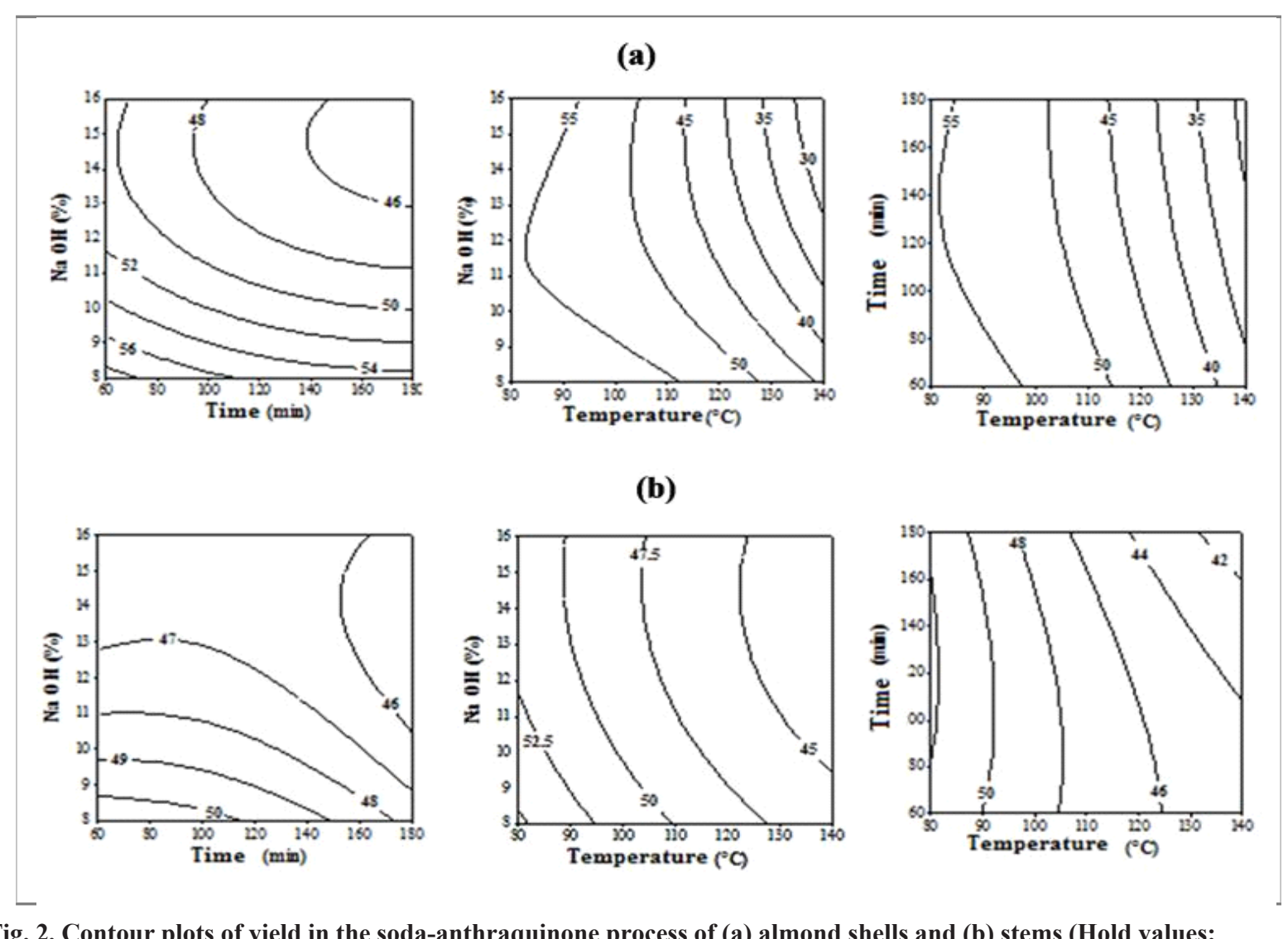

Fig. 2. Contour plots of yield in the soda-anthraquinone process of (a) almond shells and (b) stems (Hold values: temperature $=110^{\circ} \mathrm{C}$; time $=120 \mathrm{~min} ; \mathrm{NaOH}=12 \%$ ).

almond shells (), the Kappa number of almond shells (, the yield of almond stems (), and the Kappa number of almond stems (are shown in Eqs. (6) - (9) below.

$$
\begin{aligned}
\text { Yield }_{\text {ASh }}(\%)= & 28.55-2.42 X_{1}-15.68 X_{2}-11.35 X_{3}-10.28 X_{4}+10.59 X_{1}^{2}+21.61 X_{2}^{2} \\
& +16.13 X_{3}^{2}+12.46 X_{4}^{2}-1.21 X_{1} X_{2}-2.43 X_{1} X_{3}-0.25 X_{1} X_{4}-5.63 X_{2} X_{3} \\
& +0.86 X_{2} X_{4}-9.60 X_{3} X_{4}, R^{2}=91.72 \%
\end{aligned}
$$

Kappa Number $_{4 S h}=9.29-1.532 X_{1}-1.721 X_{2}-0.584 X_{3}-0.713 X_{4}-1,04 X_{1}^{2}-1,109 X_{2}^{2}-$ $0.134 X_{3}^{2}+0.300 X_{4}^{2}+1.11 X_{1} X_{2}+1.90 X_{1} X_{3}-0.80 X_{1} X_{4}+1.23 X_{2} X_{3}-0.58 X_{2} X_{4}-$ $1.490 X_{3} X_{4} ; A^{2}=90.46 \%$

Yield $_{\text {Sst }}\left(Y_{0}\right)=55.96-2.76 X_{1}-8.83 X_{2}-3.64 X_{3}-3.19 X_{4}+1.24 X_{1}^{2}+9.66 X_{2}^{2}+1.64 X_{3}^{2}+$ $1.02 X_{4}^{2}+8.00 X_{1} X_{2}-3.60 X_{1} X_{3}-5.31 X_{1} X_{4}-5.73 X_{2} X_{3}+6.57 X_{2} X_{4}-7.62 X_{3} X_{4} ; R^{2}=90.25 \%(8)$

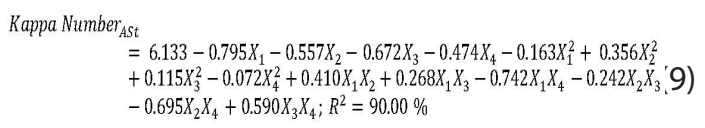

Where: $\mathrm{X}_{1}$ : $\mathrm{pH}, \mathrm{X}_{2}$ : temperature $\left({ }^{\circ} \mathrm{C}\right), \mathrm{X}_{2}$ : Sodium hypochlorite concentration $(\%)$ and $\mathrm{X}_{4}$ : time (min).

With high values of determination coefficients $\left(\mathrm{R}^{2}>90 \%\right)$, the obtained models can be considered as good statistical models with a high correlation between the observed and predicted values. It should be noted that the closer the value of $\mathrm{R}^{2}$ to unity, the better the empirical models fit the actual data within the range of the chosen variables.

The optimal process conditions obtained to maximizing the production of pure cellulose for each kind of wastes are listed in Table 6. To validate predicted values in these optimal process conditions, experiments were carried out in the same conditions and the obtained values were compared with the predicted ones. Results are presented in Table 6 . They showed that predicted and experimental values are in good agreement with differences smaller than $5 \%$. This proves that the fitted Box-Behnken models are reliable with good degree of accuracy, within the range of experimental condition.

\section{Morphological structure and fiber composition of} pulps from Prunus amygdalus

Figure 3 shows SEM pictures of crude and fibers. Almond shells and stems have an outer layer consisting of hemicellulose, lignin, and other substances as shown in Fig. 3 (A, B, C, F, 


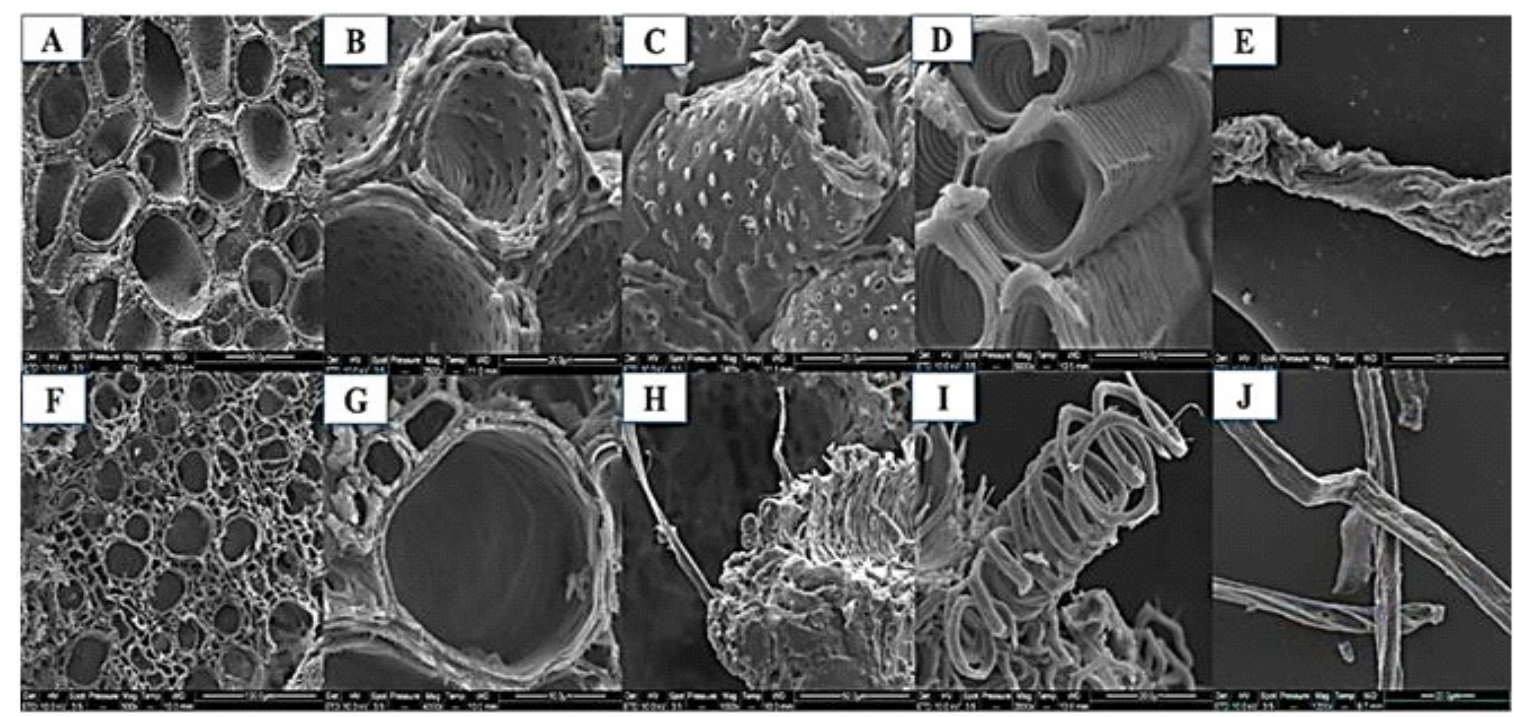

Fig. 3. SEM of (A, B and C) cross section of the almond shells, (D) spiral form in the vascular bundles of the almond shells, (E) cellulosic fibres extracted from almond shells, (F, G and $\mathrm{H}$ ) cross section of the almond stems, (I) spiral form in the vascular bundles of the almond stems and $(J)$ cellulosic fibres extracted from almond stems.

$\mathrm{G}$ and $\mathrm{H})$. The outer layer protects the cellulose in the almond shells and stems from being damaged by the microorganisms in the environment. Figure 3 (D and I) shows also the vascular bundle in almond shells and stems. Some parts of lignified thickenings in the secondary wall arrange as the spiral structure to build the vessels [30]. Furthermore, an observation of the crosssection showed the strong presence of the porous structure of the fibers forming the cellular tissues of the material.Lignin, hemicelluloses, and other extractive substances were removed from almond shells and stems by the extraction and bleaching process, and mainly cellulose was left. After extraction, the topography was entirely modified. The surface was free of impurities and a good separation of fibers was noticed (Figure 3 (E and J)). The divided fibers exhibited a cleaner surface, which indicates that all of the fiber junctions were dissolved. As regards, the dimensions of the fibres extracted from almond shells and stems are given in Table 7. The lengths of single fibres for the both residues are similar to those in other sources of biomass such as rice and wheat straw [19-27]. The fiber lengths of almond shells and stems were 380 and $518 \mu \mathrm{m}$, respectively. The fiber of almond stems was longer than other fibers of annual plants such as Switch grass $(420 \mu \mathrm{m})$. The fiber widths of almond shells and stems were 27.8 and $19.6 \mu \mathrm{m}$, respectively. The width of the fiber extracted from almond stems was smaller than the widths of other fibers such as date palm rachis $(22.3 \mu \mathrm{m})$ [24], and vine stems $(24.6 \mu \mathrm{m})[23]$. The fiber of almond stems studied was thin and long. Because of the shorter single cells, it is difficult to obtain almond shells and stems fibers that are long and fine at the same time. To form long fibers, a number of single cells must be attached together by substances such as lignin. The increase in the number of single cells and binding substances increases the width and diameter of the fiber resulting in coarse fibers.

Regarding, the two cellulose samples consisted of $85 \%$ glucose and a few amounts of xylose as recapitalized in Table 7. The existence of sugars other than glucose in cellulose due to incomplete extraction of pectin and hemicellulose. The molecular-average weight $\left(M_{w}\right)$, number-average weight $\left(M_{n}\right), D_{n}, D_{w}$ and the polydispersity $\left(D=M_{w} / M_{n}\right)$ of celluloses extracted from almond shells and stems were determined by using GPC technique. As shown in Table 7, based on GPC analyses, the DP of fibres extracted from almond stems was more important than the almond shells. In all case, these values are higher than those reported for other annual plants [2-10, 19-27].

FTIR, XRD and thermogravimetric analysis of pulps from Prunus amygdalus

The cellulose samples extracted from almond shells and stems showed four diffraction peaks at $2 \theta=14.9^{\circ}, 16.1^{\circ}, 22.2^{\circ}$ and $34.8^{\circ}$ characteristic of cellulose crystal I. The removal of lignin

Egypt. J. Chem. 62, No. 2 (2019) 


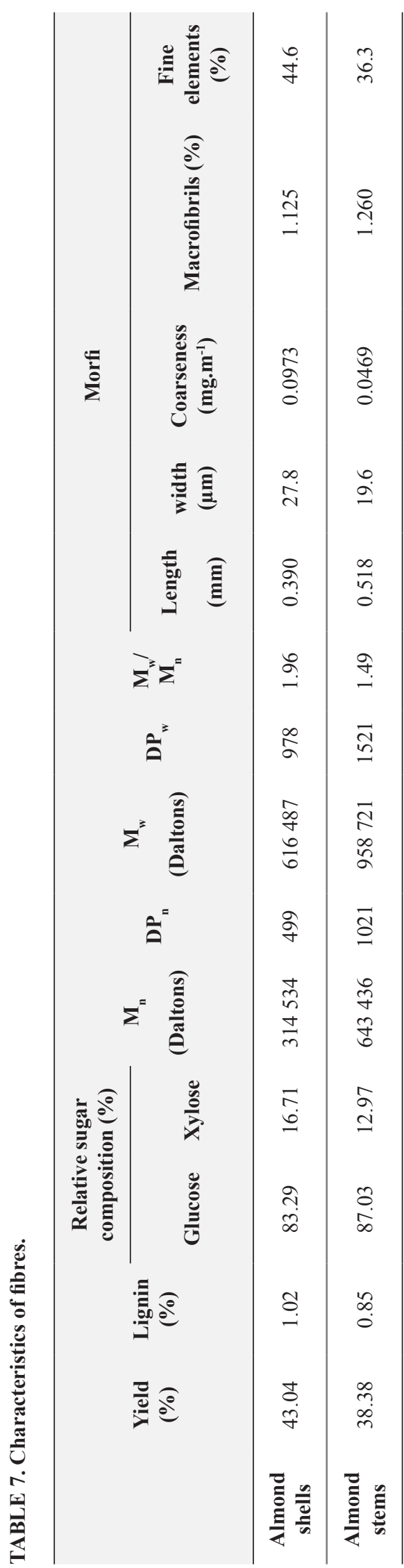

and hemicellulose from the almond shells and stems was indicated by shoulder peak at $16.1^{\circ}$ and a weak peak at $34.8^{\circ}$. In addition, the new diffraction peak at around $2 \theta=19.7^{\circ}$, which was commonly assigned to the less ordered or amorphous region of the cellulose chains shown in Fig. 4a. Fibres extracted from almond shells and stems contain 64 and $73 \%$ crystalline cellulose, respectively, which are comparable to those of cotton, flax, and kenaf which have crystallinities of 65,70 , and $60 \%$, respectively [2-8]. However, other peaks were also detected in the XRD curves. They correspond to calcium and magnesium elements. These impurities are the most common for lignocellulosic biomass, which can be easily eliminated after cooking and multi-stage washing process, since they are most probably linked with carbonates anions. These findings are in agreement with those deduced from the TGA measurements [3-7, 18-22].

FT-IR spectra are shown in Fig. 4b. The prominent band at $1064 \mathrm{~cm}^{-1}$ represents ring vibration and $\mathrm{C}-\mathrm{OH}$ bending. The band at 1160 $\mathrm{cm}^{-1}$ is attributable to the $\mathrm{C}-\mathrm{O}, \mathrm{C}-\mathrm{O}-\mathrm{C}$ stretching, with some contribution from $\mathrm{C}-\mathrm{OH}$ bending. The low intensities of the bands at 1322, 1370, and $1424 \mathrm{~cm}^{-1}$ indicates the $\mathrm{C}-\mathrm{H}$ wagging and $\mathrm{O}-\mathrm{H}$ bending; $\mathrm{CH}_{2}$ and $\mathrm{OH}$ bending; and $\mathrm{C}-\mathrm{H}$ and $\mathrm{O}-\mathrm{H}$ bending, respectively. The band at 1640 $\mathrm{cm}^{-1}$ was attributed to water in the cellulose. Spectra were providing the existence of $\mathrm{C}-\mathrm{H}$ stretch band $\left(2897-2923 \mathrm{~cm}^{-1}\right)$ and an $\mathrm{O}-\mathrm{H}$ stretch band (3406-3420 $\mathrm{cm}^{-1}$ ) corresponding to polysaccharides. The small sharp band at $900 \mathrm{~cm}^{-1}$ shows the $\beta$-glycosidic linkages[31]. The both curves of almond shells and stems confirmed that the two cellulose materials seem to be comparable in chemical composition.

Concerning, the thermal analysis of the pulps from Prunus amygdalus (shells and stems) was performed, and the results displayed in Fig. 4c indicate that both pulps behaved similarly. In fact, the thermal degradation of these fibres can be divided into three thermal stages: below 280 ${ }^{\circ} \mathrm{C}$, between 300 to $450{ }^{\circ} \mathrm{C}$ and higher than 450 ${ }^{\circ} \mathrm{C}$. The peak observed in the first region, for both examined fibres, is related to the evaporation of residual water (less than $7 \% \mathrm{w} / \mathrm{w}$ ). During the second degradation step $\left(280-380{ }^{\circ} \mathrm{C}\right)$, two degradation mechanisms are observed. The first one $\left(280-380{ }^{\circ} \mathrm{C}\right)$ involves the degradation of hemicelluloses and amorphous cellulose, whereas the second mechanism $\left(350-450{ }^{\circ} \mathrm{C}\right)$ 
(a)
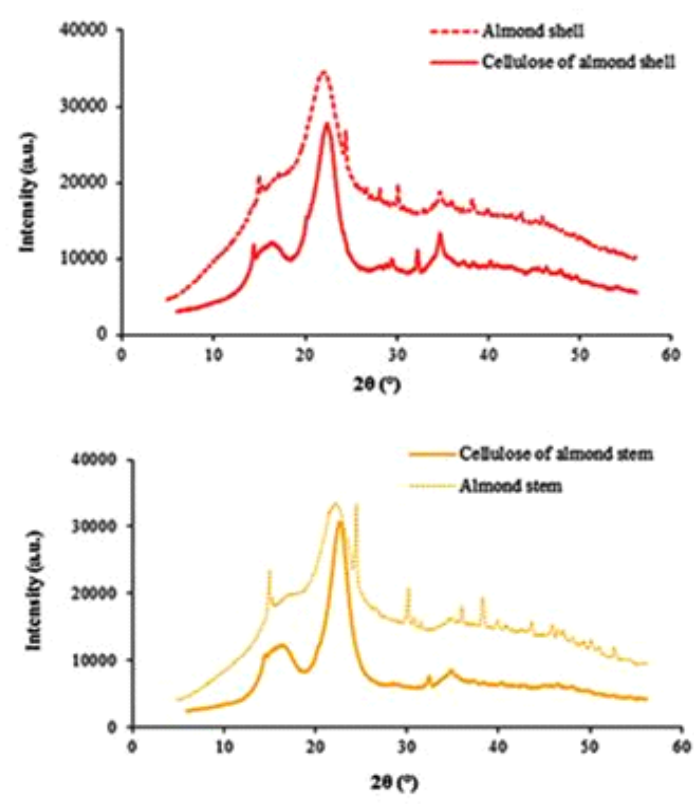

(b)

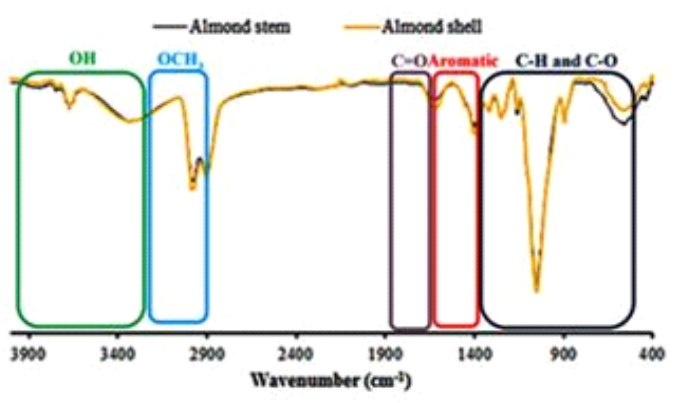

(c)

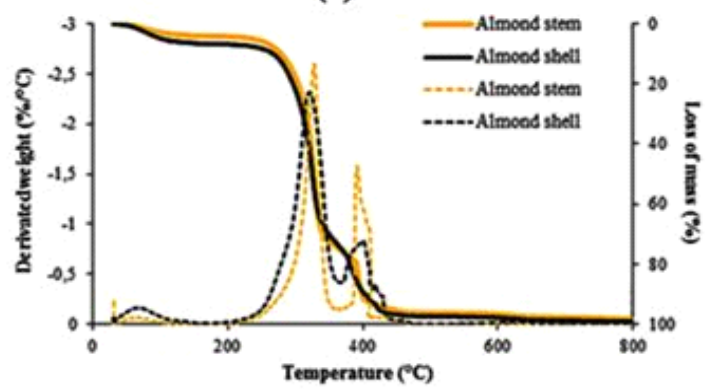

Fig. 4. (a) XRD patterns (b)FT-IR spectra of celluloses (c) TGA and DTA.

most probably consists in the degradation of the crystalline regions of cellulose. Finally, the last degradation step $(\mathrm{T}>450)$ deals with the thermal degradation of lignin. The samples seem to be ash-free pulps. The crystalline region was totally destructed and the cellulose pyrolyzed into monomer of d-glucopyranose, which decomposed into free radical[32].

\section{Conclusion}

Tunisian almond shells and stems could be considered an interesting and promising source of cellulosic fiber for papermaking thanks to the abundance and renewability of this plant. The chemical composition showed that the fibers were rich with biopolymers (carbohydrate content $60 \%$ ). The pulping of these raw materials for fibers was performed by a soda-anthraquinone process, which gave a good yield (40\%) with a Kappa number about 5-9. The obtained results show potential sources of cellulose fibres, with a view to using them in several applications, such as composite materials, papermaking, cellulose derivatives etc.

\section{Acknowledgments}

The authors gratefully express their sincere gratitude to Prof. Dr. Mohamed Naceur Belgacem (Director of Pagora-INP Grenoble, France) for his Egypt. J. Chem. 62, No. 2 (2019) help and availability. This work was financially supported by the "CMPTM (17TM22)" program of the Tunisia-Morocco and the "PHC Utique" program of the French Ministry of Foreign Affairs and Ministry of higher education and research and the Tunisian Ministry of higher education and scientific research in the CMCU project number $18 \mathrm{G} 1132$.

\section{References}

1. Moussa, I., Baaka, N., Khiari, R., Moussa, A., Mortha, G., \& Mhenni, M. F., Application of Prunus amygdalus By-products in Eco-friendly Dyeing of Textile Fabrics. Journal of Renewable Materials, 6(1), 55-67 (2018).

2. Khiari, R. Valorization of agricultural residues for cellulose nanofibrils production and their use in nanocomposite manufacturing. International Journal of Polymer Science., 2017 (2017).

3. Khiari, R., \& Belgacem, M. N. Potential for using multiscale Posidonia oceanica waste: Current status and prospects in material science. Lignocellulosic Fibre and Biomass-Based Composite Materials: Processing, Properties and Applications, 447-471 (2017).

4. Mechi, N., Khiari, R., Ammar, M., Elaloui, E., \& Belgacem, M. N. Preparation and application of Tunisian phosphogypsum as fillers in papermaking made from Prunus amygdalus and Tamarisk sp. 
Powder Technology, 312, 287-293 (2017).

5. Mechi, N., Khiari, R., Elaloui, E., \& Naceur Belgacem, M. Preparation of paper sheets from cellulosic fibres obtained from Prunus amygdalus and Tamarisk sp. Cellulose Chemistry Technology, 50 (7-8), 863-872 (2016).

6. Naili, H., Jelidi, A., Limam, O., \& Khiari, R. Extraction process optimization of Juncus plant fibres for its use in a green composite. Industrial Crops and Products, 107, 172-183 (2017).

7. Khiari, R., Marrakchi, Z., Mauret, E., Belgacem, N., Mhenni, F., \& Oueslati, H. Posidonia oceanica, date palm rachis and alfa from Tunisia as sources of cellulosic fibres. In 16th International Symposium on Wood, Fiber and Pulping Chemistry Proceedings, ISWFPC.133-138 (2011).

8. Marrakchi, Z., Khiari, R., Oueslati, H., Mauret, E., \& Mhenni, F. Pulping and papermaking properties of Tunisian Alfa stems (Stipa tenacissima)-Effects of refining process. Industrial Crops and Products. 34(3), 1572-1582 (2011).

9. Khiari, R., Mauret, E., Belgacem, M. N., \& Mhemmi, F. Tunisian date palm rachis used as an alternative source of fibres for papermaking applications. BioResources, 6(1), 265-281 (2011).

10. Khiari, R., Mhenni, M. F., Belgacem, M. N., \& Mauret, E. Valorisation of Vegetal Wastes as a Source of Cellulose and Cellulose Derivatives. Journal of Polymers and the Environment, 19(1), 80-89 (2011).

11. Hassan, M. L., Abou-Zeid, R. E., Fadel, S. M., ElSakhawy, M., \& Khiari, R. Cellulose nanocrystals and carboxymethyl cellulose from olive stones and their use to improve paper sheets properties. International Journal of Nanoparticles, 7(3-4), 261-277 (2014).

12. El-Gendy, A., Abou-Zeid, R. E., Salama, A., Diab, M. A., \& El-Sakhawy, M. TEMPOoxidized cellulose nanofibres/polylactic acid/ $\mathrm{TiO} 2$ as antibacterial bionanocomposite for active packaging. Egyptian Journal of Chemistry, 60(6), (2017).

13. El Gendy, A., Khiari, R., Bettaieb, F., Marlin, N., \& Dufresne, A. Preparation and application of chemically modified kaolin as fillers in Egyptian kraft bagasse pulp. Applied Clay Science, 101, 626-631 (2014).

14. Abou-Zeid, R. E., Hassan, E. A., Bettaieb, F., Khiari, R., \& Hassan, M. L. Use of Cellulose and Oxidized Cellulose Nanocrystals from Olive Stones in Chitosan Bionanocomposites. Journal of Nanomaterials, 2015 (2015).

15. Fahmy, Y., El-Wakil, N. A., El-Gendy, A.
A., Abou-Zeid, R. E., \& Youssef, M. A. Plant proteins as binders in cellulosic paper composites. International Journal of Biological Macromolecules, 47(1), 82-85 (2010).

16. Abou-Zeid, R. E., Elwakil, N.,. and Fahmy, Y. Thermoplastic Composites from Natural Reed Fibres. Egypt. J. Chem., 58(3), 287-298 (2015).

17. Wise, LE., Murphy M.,and D'Addieco A.A. Chlorite holocellulose, its fractionation and bearing on summative wood analysis and on studies on the hemicelluloses, Paper Trade J.122(2), 35 (1946).

18. Segal, L., Creely, J.J., Martin,A.E. and Conrad, C.M. An Empirical Method for Estimating the Degree of Crystallinity of Native Cellulose Using the X-Ray Diffractometer. Textile Research Journal, 29, 786 (1959).

19. Fan, L. T., Lee, Y.-H., \& Beardmore, D. H. Mechanism of the enzymatic hydrolysis of cellulose: Effects of major structural features of cellulose on enzymatic hydrolysis. Biotechnology and Bioengineering, 22(1), 177-199 (1980).

20. Ramos, L. P., Breuil, C., Kushner, D. J., \& Saddler, J. N. Steam Pretreatment Conditions for Effective Enzymatic Hydrolysis and Recovery Yields of Eucalyptus viminalis Wood Chips. Holzforschung, 46(2), 149-154 (1992).

21. Patel, M. M., \& Bhatt, R. M. Optimisation of the alkaline peroxide pretreatment for the delignification of rice straw and its applications. Journal of Chemical Technology \& Biotechnology, 53(3), 253-263 (2007).

22. Jiménez, L., Pérez, A., de la Torre, M. J., Moral, A., \& Serrano, L. Characterization of vine shoots, cotton stalks, Leucaena leucocephala and Chamaecytisus proliferus, and of their ethyleneglycol pulps. Bioresource Technology, 98(18), 3487-90 (2007).

23. Mansouri, S., Khiari, R., Bendouissa, N., Saadallah, S., Mhenni, F., \& Mauret, E. Chemical composition and pulp characterization of Tunisian vine stems. Industrial Crops and Products, 36(1), 22-27 (2012).

24. Khiari, R., Mhenni, M. F., Belgacem, M. N., \& Mauret, E. Chemical composition and pulping of date palm rachis and Posidonia oceanica - A comparison with other wood and non-wood fibre sources. Bioresource Technology, 101(2), 775780 (2010).

25. Antunes, A., Amaral, E., \& Belgacem, M. N. Cynara cardunculus L.: Chemical composition and soda-anthraquinone cooking. Industrial Crops and Products, 12(2), 85-91 (2000).

26. Pasquini, D., Teixeira, E. de M., Curvelo, A. A. da 
S., Belgacem, M. N., \& Dufresne, A. Extraction of cellulose whiskers from cassava bagasse and their applications as reinforcing agent in natural rubber. Industrial Crops and Products, 32(3), 486-490 (2010).

27. Reddy, N., \& Yang, Y. Structure and properties of high quality natural cellulose fibres from cornstalks. Polymer, 46(15), 5494-5500 (2005).

28. Chia, C. H., Zakaria, S., Nguyen, K. L., \& Abdullah, M. Utilisation of unbleached kenaf fibres for the preparation of magnetic paper. Industrial Crops and Products, 28(3), 333-339 (2008).

29. Alemdar, A., \& Sain, M. Isolation and characterization of nanofibres from agricultural residues - Wheat straw and soy hulls. Bioresource Technology, 99(6), 1664-1671 (2008).

30. Suryanto, H., Marsyahyo, E., Irawan, Y. S., \& Soenoko, R. Morphology, Structure, and Mechanical Properties of Natural Cellulose Fiber from Mendong Grass (Fimbristylis globulosa). Journal of Natural Fibres, 11(4), 333-351 (2014).

31. Reddy, K. O., Uma Maheswari, C., Muzenda, E., Shukla, M., \& Rajulu, A. V. Extraction and Characterization of Cellulose from Pretreated Ficus (Peepal Tree) Leaf Fibres. Journal of Natural Fibres, 13(1), 54-64 (2016).

32. Pouriman, M., Caparanga, A. R., Ebrahimi, M., \& Dahresobh, A. Characterization of Untreated and Alkaline-Treated Salago Fibres (Genus Wikstroemia Spp.). Journal of Natural Fibres, 15(2), 296-307 (2018).
33. Caballero, R., Rebolé, A., Barro, C., Alzueta, C., Treviño, J., \& García, C. Farming practices and chemical bases for a proposed quality standard of vetch-cereal hays. Field Crops Research, 47(2), 181-189 (1996)

34. Bulut, Y., \& Tez, Z. Adsorption studies on ground shells of hazelnut and almond. Journal of Hazardous Materials, 149(1), 35-41 (2007).

35. Pirayesh, H., \& Khazaeian, A. Using almond (Prunus amygdalus L.) shell as a bio-waste resource in wood based composite. Composites Part B: Engineering, 43(3), 1475-1479 (2012).

36. Mourão, P. A. M., Laginhas, C., Custódio, F., Nabais, J. M. V., Carrott, P. J. M., \& Carrott, M. M. L. R. Influence of oxidation process on the adsorption capacity of activated carbons from lignocellulosic precursors. Fuel Processing Technology, 92(2), 241-246 (2011).

37. Nabarlatz, D., Torras, C., Garcia-Valls, R., \& Montané, D. Purification of xylo-oligosaccharides from almond shells by ultrafiltration. Separation and Purification Technology, 53(3), 235-243 (2007).

38. Thomas Klasson, K., Ledbetter, C. A., Wartelle, L. H., \& Lingle, S. E. Feasibility of dibromochloropropane (DBCP) and trichloroethylene (TCE) adsorption onto activated carbons made from nut shells of different almond varieties. Industrial Crops and Products, 31(2), 261-265 (2010).

(Received 11/8/2018; accepted 27/9/2018)

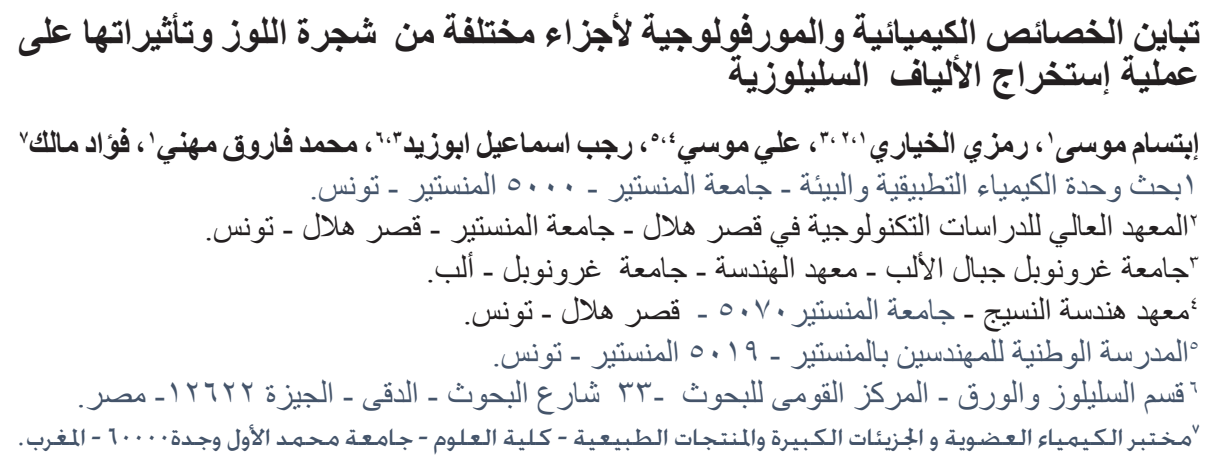

أجري تحليل كيميائي ومورفولوجي لأجزاء مختلفة من شجرة اللوز (قشور وأغصان اللوز) من أجل تقييم

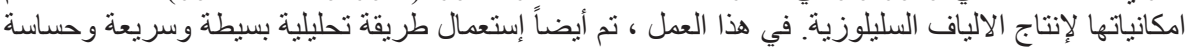

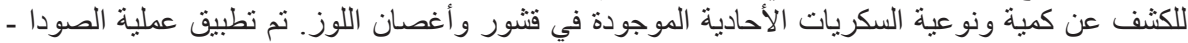

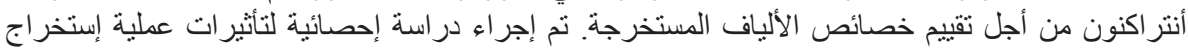

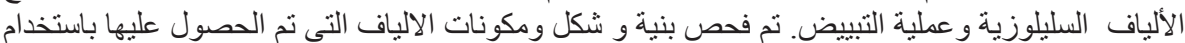
عدة تقنيات تكنولوجية حديثة. 